GRASAS Y ACEITES, 63 (2), ABRIL-JUNIO, 209-213, 2012, ISSN: 0017-3495

DOI: $10.3989 /$ gya.096311

\title{
Antioxidant activity of olive oil mill wastewater obtained from different thermal treatments
}

\author{
By A.M. Giuffrè̀, V. Sicari, A. Piscopo and L. Louadj \\ Department of Biotechnologies for Agricultural Food and Environmental Monitoring (Bio.M.A.A.), \\ Mediterranean University of Reggio Calabria, Contrada Melissari, 89124 (RC), Italy \\ ${ }^{*}$ Corresponding author: amgiuffre@ unirc.it
}

\section{RESUMEN}

Actividad antioxidante del alpechín obtenido con diferentes tratamientos térmicos.

En la industria alimentaria, el alpechín se considera un subproducto debido a la presencia de compuestos bioestáticos, con una alta tasa de contaminación, particularmente los fenoles. Además, durante el procesado de la aceituna, la generación de una gran cantidad de este subproducto supone un problema ecológico y económico para los productores. Es importante la reutilización de este agua de desecho para obtener compuestos útiles. Para purificar el agua de desecho es necesario el desarrollo de operaciones que modifiquen su contenido orgánico, para poder obtener agentes fertilizantes y/o recuperar sustancias con un alto valor añadido como los compuestos fenólicos, que actualmente están reconocidos científicamente como moléculas con una elevada actividad antioxidante. Se realizó un análisis cromatográfico de dichos compuestos para caracterizar las diferentes concentraciones en el alpechín, y posteriormente se determinó el poder reductor de los extractos. El tratamiento térmico del alpechín en rotavapor y en estufa incrementó la eficiencia en la captura de radicales. Estos resultados pueden correlacionarse con la posibilidad de recuperar y reutilizar este tipo de desecho debido a sus propiedades antioxidantes.

PALABRAS CLAVE: Alpechín - Capacidad antioxidante - Polifenoles - Radical DPPH

\section{SUMMARY}

Antioxidant activity of olive oil mill wastewater obtained from different thermal treatments.

In food industry, Olive Oil Mill Wastewater (OOMWW) is considered a by-product because of the presence of biostatic compounds with a high polluting rate, in particular phenols. Moreover, during olive oil processing, a large amount of this by-product constitutes an ecological and economical problem for the producers. To reevaluate this by-product, the reuse of this wastewater to obtain useful compounds appears to be very important. In order to purify the wastewater, the development of operations that modify its organic content seems necessary for obtaining of eventual fertilizing agents and/or to recover substances with a high added value such as phenolic compounds, which are currently recognized scientifically as molecules with a high antioxidant activity. A chromatographic analysis of these compounds was conducted to characterize different concentrations of wastewater and the reducing power of the extracts was measured. The thermal treatment of olive oil mill wastewater in a rotary evaporator and in an oven involved an increase in radical scavenging efficiency. These results could be correlated with the possibility of recovering and reusing this type of waste for its antioxidant properties.

KEY-WORDS: Antioxidant capacity - DPPH' radical Olive oil mill waste water - Polyphenols.

\section{INTRODUCTION}

Olives and olive oil are foods which are particularly rich in antioxidant biomolecules, named polyphenols. The olive oil market has recently expanded, since the "Mediterranean diet" is widely appreciated throughout the World by consumers who pay more attention to both health and nutritional food aspects (Key, 1995).

Olive processing produces OOMWW, which represents the main environmental problem and consists of several vegetable compounds (mineral but particularly organic substances), coming from the olive pulp through olive oil processing and equipment wash water and diluting water for olive paste in a continuous extraction system (threephases decanter). Continuous three-phase extraction systems are still widely used in olive oil mills, especially in Italy, where in most cases they have not yet been replaced by more recent twophase extraction systems, which involve a reduced volume of OOMWW but an increased concentration in organic matter (Roig et al., 2006). The threephase extraction system involves the addition of large amounts of water (up to $50 \mathrm{~L} 100 \mathrm{Kg}^{-1}$ olive paste) resulting in the worldwide production of more than 30 million $\mathrm{m}^{3}$ per year of OOMWW (Borja et al., 1997). Water in the olive composition represents $40-50 \%$ of the pulp weight whereas the wash water for olive oil processing corresponds to $5 \%$ of processed olive weight and wash water equipment represent 5-10\%. Therefore, wastes produced by traditional olive oil extraction system (discontinuous type) correspond to $50-60 \%$ of the processed drupe weight. In the case of continuous extraction systems the water used to thin out olive pastes during oil extraction has to be considered. The wastewater production has consequently increased and achieved values of $90-120 \%$ of the processed olive weight (Mouncif et al., 1993). 
These abundant volumes of wastewater have high values of Biological Oxygen Demand $\left(\mathrm{BOD}_{5}\right)$ and Chemical Oxygen Demand (COD) because of their content of organic matter. So OOMWW produced during the olive oil extraction process, consists of an effluent liquid that possesses a considerable polluting charge and causes evident problems of disposal in the European areas of olive cultivation. OOMWW shows a low leaning towards biological treatments, which would allow for its disposal due to the consistent presence of organic substances including sugars, tannins, polyphenols, polyalcohols, pectins, and lipids (D'Annibale et al., 1998). On the one hand, phenols are responsible of the high values of $C O D$ and $\mathrm{BOD}_{5}$, on the other hand if recovered, they might be reused as natural antioxidants as a replacement for BHA (2(3) tertbutyl-4-hydroxyanisole), BHT (3,5-di-tert-butyl-4hydroxytoluene), TBHA (tert-butyl-hydroxyl-amineacetate), NDGA (nord-hydroguaiaretic acid) and other synthetic antioxidants (ascorbic acid, gallate propyl, gallateottil, gallatedodecyle). Phenol recovery would result in a significant reduction in the COD and $\mathrm{BOD}_{5}$ values of OOMWW. The phenolic composition of OOMWW has been studied in several recent works (Della Greca et al., 2004; Obied et al., 2005; Servili et al., 1999). The phenolic composition of OOMWW is very different from that of the olive fruit. Olives are rich in secoiridoid glucosides whereas OOMWW showed a high concentration of secoiridoid derivatives such as hydroxytyrosol and the dialdehydic form of decarboxymethyl oleuropein aglycon. The OOMWW phenolic fraction is characterized by a great complexity, as demonstrated by Bianco et al. (2003); one of the most abundant and very interesting compounds from a nutritional point of view is hydroxytyrosol, which has been widely studied, demonstrating its antioxidant and beneficial health properties as well as its good bioavailability. Hydroxytyrosol scavenges free radicals (Visioli et al., 1999) and inhibits human low-density lipoprotein (LDL) oxidation (Aruoma et al., 1998; Casalino et al., 2002; Deiana et al., 1999). For economic reasons, OOMWW is usually concentrated in evaporation ponds and left to dry throughout the summer season (Borja et al., 1992; Benitez et al., 1997). The polluting power of olive oil mill wastewater depends on the high content of organic substances (sugars, pectins, lipids, nitrogen compound, alcohols and acids). Generally COD is between 100 and $190 \mathrm{~g} \mathrm{~L}^{-1}$ of oxygen and the $\mathrm{BOD}_{5}$ is $50-140 \mathrm{~g} \mathrm{~L}^{-1}$ of oxygen. The polluting charge is principally due to the high concentrations of polyphenols $\left(1-10 \mathrm{~g} \mathrm{~L}^{-1}\right)$ that have different molecular weights, strong antimicrobial and phytotoxic properties and are also resistant to biological degradation.

The recovery of phenolic antioxidants by the waste seems achievable to produce substances industrially exploitable as supplemental food and the phytochemicals as chemical preservative compounds which can replace synthetic products. If the objective can be reached, significant economic gains can be obtained olive oil production. Therefore, in the present work, a study of the recovery of phenolic fraction from the olive oil mill wastewater has been carried out because of its high antioxidant properties. The tests mainly revealed the viability of the extraction of phenols from wastewater and the recovery of the same fraction from the water previously concentrated. In addition, an evaluation of the antioxidant capacity has been successively conducted on several fractions obtained from differently treated wastewater.

\section{MATERIALS AND METHODS}

\subsection{Materials}

Fresh olive oil mill wastewater was supplied by the continuous three-phases of olive oil production process located in Reggio Calabria Province (Italy). The samples, collected in October 2009, were stored at room temperature before analyses. OOMWW was submitted to the following treatments: concentration at $50 \%$ of the initial volume in a rotary evaporator at $50^{\circ} \mathrm{C}\left(\mathrm{OOMWW}_{\mathrm{R}}\right)$ and concentration at $50 \%$ of the initial volume in an oven at $80^{\circ} \mathrm{C}$ $\left(\mathrm{OOMWW} \mathrm{W}_{\mathrm{O}}\right)$. These tests were compared with the control (OOMWW).

\subsection{Chemicals}

Acetonitrile, methanol and acetic acid were HPLC-grade solvents purchased from Carlo Erba (Milan, Italy); Folin-Ciocalteu phenol reagent, sodium carbonate anhydrous, tyrosol, gallic acid, vanillic acid, $p$-coumaric acid, ferulic acid were obtained from Fluka (Buchs, Switzerland); oleuropeinglucoside was supplied from Extrasynthèse (Genay, France). 2,2 diphenyl-1-picrylhydrazyl ( $\mathrm{DPPH}^{\circ}$ ) was obtained from Sigma-Aldrich Chemical Co. (St Louis, MO, USA).

\subsection{Methods}

The dry matter content was determined by oven drying at $105^{\circ} \mathrm{C}$ up to a constant weight. The $\mathrm{pH}$ values were measured using a $\mathrm{pH}$-meter (Crison basic 20 , with a $50 \mathrm{~cm}$ electrode). These analyses were performed on three homogenized samples. The total polyphenols were extracted from olive oil mill wastewater following the Folin-Ciocalteu assay (Waterman and Mole, 1994): the samples were subjected to extraction with an ethylacetate/acetone solution $(2: 1, \mathrm{v} / \mathrm{v})$ and then dehydration in a rotary evaporator and the residue was recovered in a $1 \mathrm{~mL}$ methanol/water solution $(4: 1, \mathrm{v} / \mathrm{v}) .2 .5 \mathrm{~mL}$ of FolinCiocalteu's reagent and $5 \mathrm{~mL}$ of a $20 \%$ sodium carbonate solution were added to the phenolic extract in a $100 \mathrm{~mL}$ volumetric flask, filled to volume with deionized water and allowed to stand for 6 hours at room temperature and in the dark. The absorbance was measured at $725 \mathrm{~nm}$ using a Perkin-Elmer UV-Vis Lambda2 spectrometer. The total phenol concentrations were expressed as milligrams of 
gallic acid equivalents per liter of fresh weight. Measurements were made in triplicate. To obtain extracts for HPLC analysis, $10 \mathrm{~mL}$ of olive oil mill wastewater, previously acidified to $\mathrm{pH} 2$ with $\mathrm{HCl}$, were diluted with $15 \mathrm{~mL}$ of hexane and then centrifuged at $3000 \mathrm{rpm}$ for $5 \mathrm{~min}$. The dilution was repeated twice, then the OOMWW was mixed with $10 \mathrm{~mL}$ of ethyl acetate and the mixture was vigorously shaken and centrifuged for $5 \mathrm{~min}$ at $3000 \mathrm{rpm}$. The phases were separated and the extraction was repeated four times. The organic extract dissolved in ethyl acetate was evaporated under vacuum at $40^{\circ} \mathrm{C}$ in a rotary evaporator. The residue was dissolved in $4 \mathrm{~mL}$ of methanol:water $1: 1$ and analyzed by HPLC. Qualitative and quantitative evaluations of phenolic compounds were conducted. The analyses were performed by an HPLC Knauer (Asi, Advanced Scientific Instruments, Berlin, Germany) smartline pump 1000, a UV Waters 486 detector coupled with a reversed phase C18 column, $120 \AA$, $4 \mu \mathrm{m}, 4.6 \mathrm{~mm}$ ID $\times 250 \mathrm{~mm}, 5 \mu \mathrm{m}$ particle size (Polymer Laboratories); guard column (4.6 mm ID, $5 \mu \mathrm{m}$ analytical particle size); $1 \mathrm{~mL} \mathrm{~min}^{-1}$ flow; mobile phase: $A=$ acetic acid : water solution (2:98, v:v) and $\mathrm{B}=$ methanol. The following gradient was used: $95 \% A$ and $5 \% \mathrm{~B}$ at the starting time, $70 \% \mathrm{~A}$ and $30 \% \mathrm{~B}$ at $25 \mathrm{~min}, 60 \% \mathrm{~A}$ and $40 \% \mathrm{~B}$ at $35 \mathrm{~min}, 52 \%$ $A$ and $48 \%$ B at $40 \mathrm{~min}, 30 \% \mathrm{~A}$ and $70 \% \mathrm{~B}$ at $50 \mathrm{~min}$, $100 \% \mathrm{~B}$ at $55 \mathrm{~min}$. The eluents were detected at $280 \mathrm{~nm}$ at room temperature using gallic acid as internal standard $\left(0.8 \mathrm{mg} \mathrm{mL}^{-1}\right)$. The samples were filtered through a $0.45 \mu \mathrm{m}$ membrane filter and $10 \mu \mathrm{L}$ of this solution were injected into the column. The response factors were similar to those determined by Mateos et al. (2001). The antioxidant activity was measured according to the methodology described by BrandWilliams et al. (1995) based on the bleaching reaction of a stable free radical, 2,2-diphenyl-1picrylhydrazyl (DPPH') (Carlo Erba, MI, Italy) in the presence of the samples. The samples were left to react for $2 \mathrm{~h} 30$ min in a cuvette containing $3 \mathrm{~mL}$ of a methanol solution $6 \cdot 10^{-5} \mathrm{M}$ of $\mathrm{DPPH}$. Analysis was carried out at $515 \mathrm{~nm}$ wavelength and at ambient temperature, thus the risk of thermal degradation of the tested molecules is eliminated (Bondet et al., 1997) to obtain a decrease in absorbance by the $\mathrm{DPPH}^{\circ}$ radical (the decoloration curve of the radical follows very slow kinetics). A graph of absorbance vs. time shows that its decrease followed a $4^{\text {th }}$ order kinetic $\left(r^{2} \geq 0.99\right)$. Antioxidant capacity was expressed as $-\mathrm{OD}^{-3} \mathrm{~min}^{-1} \mathrm{~mL}^{-1}$ by the reaction rate $\mathrm{k}$ and calculated by the following equation: $\left(1 / A^{3}\right)-(1 /$ $\left.A_{0}^{3}\right)=-3 k t$ where $A_{0}$ is the initial optical density and $A$ is the optical density at increasing time t, OD is optical density.

\subsection{Statistical analysis}

A one-way variance analysis (ANOVA) was applied to the data to determine the significant differences $(P \leq 0.05)$. SPSS Software (Version 11.0, SPSS Inc., Chicago, IL, USA) was used for data processing.

\section{RESULTS AND DISCUSSION}

In Table 1, results of the $\mathrm{pH}$ values and the dry matter contents of the samples are reported. For the applied operations, the percentage of dry matter successively increased from 6.02 to $10.37 \%$, in the concentrated samples. The $\mathrm{pH}$ value did not significantly vary despite the treatments.

The total phenols were reported in Table 2 as $\mathrm{mg}$ of gallic acid equivalents (GAE) by a standard curve reference $\left(y=1.2699 \times-0.0142, r^{2}=0.9988\right)$. The highest total phenol content $\left(238.50 \mathrm{mg} \mathrm{L}^{-1}\right)$ was evidently found in the fresh OOMWW extract, whereas, the original level of GAE decreased as consequence of the dehydration treatments and the successive oxidation reaction due to polyphenol oxidase (PPO) activity as reported in a previous work (Marsilio et al., 2001). The total phenol levels determined in this way were not the absolute measurements of the amount of phenolic compounds but were in fact based on their reducing chemical capacity relative to an equivalent reducing capacity of gallic acid (Mc Donald et al., 2001).

The identification of phenolic compounds in the OOMWW extracts was performed by HPLC-UV. The HPLC analysis confirmed hydroxytyrosol as the major representative phenolic compound as reported in literature (Fki et al., 2005). In fact, its concentration ranged from 24.63 to 64.9 to $\mathrm{mg} \mathrm{L}^{-1}$ in the samples. Vanillic acid was the second represented one and tyrosol, ferulic acid, p-coumaric acid, 3,4 DHPEA-EA (the dialdehydic form of decarboxymethyl oleuro pein aglicon) and HPEA-EDA (the dialdehydic form of decarboxymethyl ligstroside aglicon) were present in lower amounts.

The different phenolic compounds responded similarly to the treatment of concentration. Their amount decreased after applying a high thermal process $\left(80^{\circ} \mathrm{C}\right)$ but, it increased significantly as a result of the rotary evaporator with a lower temperature. This could be considered to reduce the polyphenol content in the wastewater during a high thermal treatment, such as concentration in the oven. A general decrease in the single phenol quantity in dry matter was observed and revealed that the molecules showed a general degradation trend after the wastewater concentration. The percentage of the phenolic compounds followed different trends.

Table 1

pH values and dry matter contents of different OOMWW

\begin{tabular}{lcc}
\hline \multicolumn{1}{c}{ Samples } & pH & Dry matter (\%) \\
\hline OOMWW & $4.80^{\mathrm{a}}$ & $6.02^{\mathrm{b}}$ \\
OOMWW $_{\mathrm{R}}$ & $4.78^{\mathrm{a}}$ & $10.37^{\mathrm{a}}$ \\
OOMWW $_{\circ}$ & $4.75^{\mathrm{a}}$ & $10.37^{\mathrm{a}}$ \\
Sig. & n.s. & $*$ \\
\hline
\end{tabular}

Data represent the mean of three replicates. Data followed by different letters are significantly different by Duncan's multiple range test. ${ }^{*}$ Significance at $P \leq 0.05$. ${ }^{* *}$ Significance at $P \leq 0.01$, n.s. not significant. 
Table 2

Phenolic composition and total phenols of different OOMWW

\begin{tabular}{|c|c|c|c|c|c|c|c|c|c|c|}
\hline & \multicolumn{3}{|c|}{ oomww } & \multicolumn{3}{|c|}{ OOMWW $_{\mathrm{R}}$} & \multicolumn{3}{|c|}{ OOMWW $_{0}$} & \multirow{2}{*}{ Sig. } \\
\hline & $\mathrm{mgL}^{-1}$ & $\mathrm{mgL} \mathrm{d.m.}{ }^{-1}$ & $\%$ & $\mathrm{mgL}^{-1}$ & $\mathrm{mgL}$ d.m. ${ }^{-1}$ & $\%$ & $\mathrm{mgL}^{-1}$ & $\mathrm{mgL}$ d.m. ${ }^{-1}$ & $\%$ & \\
\hline Hydroxytyrosol & $57.29^{b}$ & 951.66 & 40.74 & $63.84^{\mathrm{a}}$ & 615.62 & 40.69 & $24.83^{c}$ & 239.39 & 38.75 & $* *$ \\
\hline Tyrosol & $14.52^{b}$ & 241.11 & 10.32 & $21.02^{\mathrm{a}}$ & 202.65 & 13.39 & $11.27^{\mathrm{C}}$ & 108.68 & 17.59 & ** \\
\hline Vanillic acid & $52.64^{\mathrm{a}}$ & 874.34 & 37.43 & $52.68^{\mathrm{a}}$ & 507.96 & 33.57 & $18.20^{b}$ & 175.46 & 28.4 & ** \\
\hline Ferulic acid & $8.75^{\mathrm{b}}$ & 145.27 & 6.22 & $9.81^{\mathrm{a}}$ & 94.6 & 6.25 & $4.78^{\mathrm{c}}$ & 46.05 & 7.45 & ** \\
\hline$p$-Coumaric acid & $5.41^{b}$ & 89.78 & 3.84 & $6.47^{\mathrm{a}}$ & 62.34 & 4.12 & $4.90^{\circ}$ & 47.25 & 7.65 & * \\
\hline 3,4-DHPEA-EA & $1.05^{\mathrm{a}}$ & 17.36 & 0.74 & $1.08^{\mathrm{a}}$ & 10.37 & 0.69 & $0.07^{\mathrm{b}}$ & 0.68 & 0.11 & $* *$ \\
\hline HPEA-EDA & $0.90^{\mathrm{b}}$ & 14.95 & 0.64 & $1.50^{\mathrm{a}}$ & 14.46 & 0.96 & $0.13^{c}$ & 1.21 & 0.2 & ** \\
\hline Total phenols(GAE) & $238.5^{\mathrm{a}}$ & 3961.79 & & $162.26^{b}$ & 1564.71 & & $124.05^{c}$ & 1196.24 & & ** \\
\hline
\end{tabular}

Data represent the mean of three replicates. Data followed by different letters are significantly different by Duncan's multiple range test. * Significance at $P \leq 0.05$. ${ }^{*}$ Significance at $P \leq 0.01$, n.s. not significant.

Although the ratio between the single phenols was generally constant, concentration in the oven seemed to increase the percentage values of tyrosol, ferulic acid and $p$-coumaric acid, whereas the concentration by rotavapor had the same effect only for the tyrosol and the HPEA-EDA content. In addition, hydroxytyrosol, vanillic acid and the 3,4-DHPEA-EA decreased proportionally after both thermal treatments.

As confirmed by Soleas (1997), antioxidant activity is highly correlated to the polyphenols, but not all phenolic compounds possess the same biological activity and their chemical compositions are strongly influenced by technological treatments as studied by Manzocco et al. (1998). The antioxidant compounds with molecular structures, identical to those of polyphenols, act to stop chain reactions (for example the oxidation) and form species of stable radicals after the elimination of a hydrogen atom. It is well known that many antioxidants can be significantly lost as a consequence of the processing as well as during prolonged storage (Johnson, 1991).

Nevertheless, it was recently demonstrated that thermal treatments can induce the formation of compounds with new and/or higher antioxidant properties (Nicoli et al., 1997; Anese et al., 1998). From the obtained results reported in Table 3 , it is possible to denote that no concentrated OOMWW

Table 3

Chain breaking activity of OOMWW

\begin{tabular}{lc}
\hline Samples & $\begin{array}{c}\text { Chain breaking activity } \\
\left(-\mathrm{OD}^{-3} \mathrm{~min}^{-1} \mathrm{~mL}^{-1}\right)\end{array}$ \\
\hline OOMWW & $44.3^{\mathrm{c}}$ \\
OOMWW $_{\mathrm{R}}$ & $104.73^{\mathrm{a}}$ \\
OOMWW & $77.54^{\mathrm{b}}$ \\
Sig. & $\star *$ \\
\hline
\end{tabular}

Data represent the mean of three replicates. Data followed by different letters are significantly different by Duncan's multiple range test. * Significance at $\mathrm{P} \leq 0.05$. ** Significance at $\mathrm{P} \leq 0.01$, n.s. not significant. had the lowest value of antioxidant capacity (44.3 $-O D^{-3} \cdot \mathrm{min}^{-1} \cdot \mathrm{mL}^{-1}$ ), whereas the OOMWW demonstrated a higher radical scavenging property than $\mathrm{OOMWW}_{\mathrm{O}}\left(104.73\right.$ and $77.54-\mathrm{OD}^{-3} \mathrm{~min}^{-1} \mathrm{~mL}^{-1}$, respectively).

\section{CONCLUSIONS}

The application of high concentration temperatures induced a strong reduction in total phenol content in OOMWW $\mathrm{OMh}_{\mathrm{O}}$, whereas in OOMWW the low values of GAE could be ascribed to the oxidation by PPO activity which is prolonged under those thermal conditions $\left(50^{\circ} \mathrm{C}\right)$.

A polymerization of simple phenolic compounds probably took place because of the prolonged time of exposure to the processing temperature, as also observed in other studies (Pinelo, 2005). The concentration in the rotary evaporator most likely promoted the formation of polymers so that the $\mathrm{OOMWW}_{\mathrm{R}}$ sample showed the highest antioxidant property due to the cited achieved polymerization of polyphenols unlike the non thermal treated sample. Also, the OOMWW $\mathrm{O}_{\mathrm{O}}$ sample has greater chainbreaking activity than the OOMWW, but this result could not be ascribable to the phenolic contents. During thermal treatments, besides the nutrient loss, foods can be subjected to other chemical changes such as those resulting from the Maillard reaction. This reaction, which occurs when sugars condense with free amino acids, peptides or proteins, leads to the formation of a wide variety of intermediate products (Maillard reaction products, MRPs) that can act as antioxidants (Nicoli et al., 1997). The waste water, as before mentioned, is rich in organic substances, such as sugars, proteins and polyphenols. These can take part in the Maillard reactions as they are formed during oxidative reactions. So, the loss of natural antioxidants in the heating process could be minimized or compensated by the formation of non-nutrient antioxidants such as MRPs, as demonstrated in other recent 
experiments (Manzocco et al., 2001; Madrau et al., 2009). In our study, the treatment by concentration of olive oil wastewater in a rotary evaporator and in the oven, involved an increase in its efficiency, so that this type of waste seems to be fit for a recovery and a successive reuse.

\section{REFERENCES}

Anese M, Manzocco L, Nicoli MC, Lerici CR. 1998. Antioxidant properties of tomato juice as affected by heating. J. Sci. Food Agri. 13, 132-141.

Aruoma OI, Deiana M, Jenner A, Halliwell B, Kaur M, Banni S. 1998. Effect of hydroxytyrosol found in extra virgin olive oil on oxidative DNA damage and lowdensity lipoprotein oxidation. J. Agri. Food Chem. 46, 5181-5187.

Benitez FJ, Beltran-Heredia J, Torregrosa J, Acero JL, Cercas V. 1997. Chemical pretreatment by ozone of wastewater from olive oil mills. Technol. Environ. Chem. 60, 97-109.

Bianco A, Buiarelli F, Cartoni G, Coccioli F, Jasionowska R, Margherita P. 2003. Analysis by liquid chromatography tandem mass spectrometry of biophenolic compounds in olives and vegetation waters, Part I. J. Separation Sci. 26, 409-416.

Bondet V, Brand-Williams W, Berset C. 1997. Kinetics and mechanisms of antioxidant activity using the DPPH $^{\circ}$ free radical method. Food Sci. Technol. 30, 609-615.

Borja R, Martin M, Maestro R, Alba J, Fiestas JA. 1992. Enhancement of the anaerobic digestion of olive mill wastewater by the removal of phenolic inhibitors. Biochemistry. 27, 231-237.

Borja R, Alba J, Banks CJ. 1997. Impact of the main phenolic compounds of olive mill wastewaters (OMW) on the kinetics of acetoclasticmethanogenesis. Process Biochem. 32, 121-133.

Brand-Williams, Cuvelier ME, Berset C. 1995. Use of free radical method to evaluate antioxidant activity. Food Sci. Technol. 28, 25-30.

Casalino E, Calzaretti G, Sblano C, Landriscina V, Tecce MF, Landriscina C. 2002. Antioxidant effect of hydroxytyrosol (DPE) and Mn2+ in liver of cadmiumintoxicated rats. Comp. Biochem. Phys. C133, 625-632.

D'Annibale A, Crestini C, Vinciguerra V, Giovannozzi Sermanni G. 1998. The biodegradation of recalcitrant effluents from an olive mill by a white-rot fungus. J. Am. Oil Chemists Soc. 66, 792-799.

Deiana M, Aruoma OI, Bianchi MDP, Spencer JPE, Kaur H, Halliwell B, Aeschbach R, Banni S, Dessi MA, Crongiu FP. 1999. Inhibition of peroxynitrite dependent DNA base modification and tyrosine nitration by the extra virgin olive oil-derived antioxidant hydroxytyrosol. Free Radical Biol. Med. 26, 762-769.

Della Greca M, Previtera L, Temessi F, Carrelli A. 2004. Low-molecular-weight components of olive oil mill wastewaters. Phyto-chemical Analysis. 15, 184-188.

Fki I, Allouche N, Sayadi S. 2005. The use of polyphenolicextract, purified hydroxytyrosol and 3,4-dihydroxyphenyl acetic acid from olive mill wastewater for the stabilization of refined oils: a potential alternative to synthetic antioxidants. Food Chem. 93, 197-204.

Johnson L. 1991. Thermal degradation of carotenoids and influence on their physiological functions. In Nutritional and Toxicological Consequences of Food Processing, ed. M. Friedman, Plenum Press, New York, 75-82.

Key A. 1995. Mediterranean diet and public health: personal reflections. Am. J. Clin. Nutr. 61, 1321S-1323S.

Madrau M, Piscopo A, Sanguinetti AM, Del Caro A, Poiana M, Romeo FV, Piga A. 2009. Effect of drying temperature on polyphenolic content and antioxidant activity of apricots. Eur. Food Res. Technol. 228, 441448.

Manzocco L, Anese M, Nicoli MC. 1998. Antioxidant properties of tea extracts as affected by processing. Food Sci. Technol. 31, 694-698.

Manzocco L, Calligaris S, Mastrocola D, Nicoli MC, Lerici CR. 2001. Reviews of non-enzymatic browning and antioxidant capacity in processed foods, Trends Food Sci. Technol. 11, 340-346.

Marsilio V, Campestre C, Lanza B. 2001. Phenolic compounds change during California-style ripe olive processing. Food Chem. 74, 55-60.

Mateos R, Espartero JL, Trujillo M, Rios JJ, LeónCamacho M, Alcudia F. 2001. Determination of phenols, flavones and lignans in virgin olive oils by solid-phase extraction and high-.performance liquid chromatography with diode array ultraviolet detection. J. Agri. Food Chem. 49, 141-144.

McDonald S, Prenzler PD, Antolovich M, Robards K. 2001. Phenolic content and antioxidant activity of olive extracts. Food Chem. 73, 73-84.

Mouncif M, Tamoh S, Faid M, Achka-Begdouri A. 1993. A study of chemical and microbiological characteristics of olive mill waste waters in Marocco. Grasas Aceites 44, 335-338.

Nicoli MC, Anese M, Parpinel M, Franceschi F, Lerici CR. 1997. Loss and/or formation of antioxidants during food processing and storage. Cancer Lett. 114, 71-74.

Obied HK, Allen MS, Bedgood DR, Prenzler PD, Robards K, Stockmann R. 2005. Investigation of Australian olive mill waste for recovery of biophenols. J. Agri. Food Chem. 53, 9911-9920.

Pinelo M, Del Fabbro P., Manzocco L., Nuñez MJ, NicoliMC. 2005. Optimization of continuous phenol extraction from Vitis vinifera byproducts. Food Chem. 92, 109-117.

Roig A, Cayuela ML, Sánchez-Monedero MA. 2006. An overview on olive mill wastes and their valorisation methods. Waste Manage. 26, 960-969.

Servili M, Baldioli M, Selvaggini R, Miniati E, Macchioni A, Montedoro G. 1999. High-performance liquidchromatographyevaluation of phenols in olive fruit, virgin olive oil, vegetation waters and pomace and ID- and 2D-Nuclear Magnetic Resonance characterization. J. Am. Oil Chem. Soc. 76, 873-882.

Soleas GJ, Tom Linson G, Eleftherios PD, Goldberg DM. 1997. Relative contributions of polyphenolic constituents to the antioxidant status of wine: development of a predictive model. J. Agri. Food Chem. 45, 3995-4003.

Visioli F, Romani A, Mulinacci N, Zarini S, Conte D, VincieriFF. 1999. Antioxidant and other biological activities of olive mill waste waters. J. Agri. Food Chem. 47, 3397-3401.

Waterman PG, Mole S. 1994. Analysis of phenolic plant metabolites, $1^{\text {st }}$ ed.; Blackwell Scientific publications: Oxfords U.K. 272 p. 